\section{Inocência branca e ignorância agressiva: raça, gênero $e$ colonialismo}

\section{White innocence and aggressive ignorance: race, gender, and colonialism}

WEKKER, Gloria. White innocence: paradoxes of colonialism and race. Durham/Londres, Duke University Press, 2016. 240 pp.

\section{Bruna Triana \\ https://orcid.org/0000-0002-6439-5457}

Programa de Pós-graduação em Antropologia Social da Universidade de São Paulo (PPGAS/USP), São Paulo SP, Brasil. E-mail: brunatriana@usp.br.

DOI: $10.1590 / 349909 / 2019$

Em White innocence, a antropóloga Gloria Wekker analisa os paradoxos holandeses ${ }^{1}$ de seu passado colonial e escravocrata enraizados na identidade nacional, nas tradiçóes culturais e nos processos de autorrepresentação coletiva. O projeto da autora de origem afro-surinamesa é desmistificá-los, explorando as formas pelas quais eles operam na dinâmica de constituição e expressão da identidade branca holandesa. Analisando uma diversidade ampla de materiais - de memórias e experiências pessoais a programas televisivos, de romances populares a instituiçóes públicas, de movimentos sociais e partidos a tradiçóes nacionais -, Wekker problematiza as variaçóes, as ambiguidades e as justificaçóes em que tais paradoxos operam.

Embasado, sobretudo, nas teorias decoloniais e nos estudos de gênero - bem como na ideia de interseccionalidade -, o livro é um trabalho fundamental para compreender a imagem que a Holanda projeta para si mesma e para o mundo: uma nação pequena, eticamente comprometida com valores republicanos, de tradição hospitaleira, tolerante e liberal. No entanto, para além dessa face autoconstruída e globalizada de nação liberal, Wekker denuncia o que não se revela (seja por negação, seja repressão) nas estratégias de gerenciamento da autoimagem nacional. Para tanto, a autora examina como o passado colonial, a escravidão e a questão racial são, ainda nos dias de hoje, fatores que se manifestam em diversas situaçóes e contextos, moldando, inclusive, a dinâmica e os mecanismos holandeses de autorrepresentação. Trata-se, portanto, de uma etnografia da autorrepresentação branca holandesa dominante.

Nessa medida, é importante atentar para a posição que a branquitude ocupa nesse processo. Conforme argumenta Wekker, apoiando-se em uma vasta tradição feminista negra, o fator branquitude não é reconhecido enquanto posição racial, e por isso é tomado como condição neutra, normalizada. Com efeito, o livro dialoga e opera com o conceito de "saberes localizados", de Donna Haraway, que remete à localização de quem fala e de quem escreve. Em um espectro amplo de posiçóes possíveis no interior de determinado espaço social, nossa disposição implica um impacto epistemologicamente significativo na forma e no conteúdo do enunciado emitido, o que pode servir, inclusive, para autorizar ou desautorizar discursos. Uma vez que não há igualdade de posiçôes, a localização do saber recusa a suposta "objetividade científica" e compreende que o objeto do conhecimento é ativo e nunca "um escravo do senhor que encerra a dialética apenas na sua agência e em sua autoridade de conhecimento 'objetivo" (Haraway, 1995, p. 36). Esse conceito aparece no livro de Wekker de duas formas: primeiro, na análise crítica à posição masculina e branca que, por ser dominante, não se apresenta enquanto tal, mas como condição ordinária, natural, que "produz, apropria e ordena toda a diferença" (Idem, p. 27); segundo, em relação à própria posição que a autora ocupa, enquanto mulher, negra, de origem surinamesa, lésbica, antropóloga e ativista empenhada - intelectual e politicamente -, em compreender como "a reserva de conhecimento e afeto, baseada em 400 anos de domínio imperial, cumprem um papel vital, mas não reconhecido, nos processos dominantes de produção de sentido, incluindo na produção do eu da sociedade holandesa" (p. 2). ${ }^{2}$

São três os paradoxos apresentados em relação aos processos de autorrepresentaçáo branca holandesa. O primeiro paradoxo é o da não-identificação com o outro, sobretudo imigrantes e refugiados, a despeito de o país ser uma nação de (descendentes de) migrantes e refugiados - sejam judeus de Portugal e Espanha, huguenotes, belgas, indonésios, suri- 
nameses, turcos, marroquinos. Os sinais de origem devem ser apagados; assim, mais significativo que a origem e a classe social são as diferenças visíveis no corpo, com base na cor da pele. O segundo paradoxo é a autoimagem de vítimas inocentes, sobretudo, da ocupação alemã durante a Segunda Guerra Mundial. Trata-se de uma memória focada nos horrores do holocausto, mas que apagou a imagem de perpetradores de violência, bem como a escravidáo e a colonização, da memória coletiva do país. Por fim, o terceiro paradoxo envolve a presença imperial holandesa no mundo, desde o século XVI, e a (total) ausência dessa história nos currículos educacionais, na produção de imagens nacionais, nos lugares de memória, em monumentos, literaturas e debates sobre identidade holandesa: "o fato de que a Holanda foi uma formidável nação imperial é o segredo mais bem guardado do país” (p. 13).

Esses paradoxos são enfrentados, pela antropóloga, a partir de três categorias analíticas que atravessam a obra: inocência branca, arquivo cultural e autorrepresentação branca holandesa dominante.

Entre as diversas complexidades que envolvem o racismo holandês, Wekker coloca em primeiro plano a inocência branca. O discurso da inocência reivindicação que opera, também, em outros países europeus - tem ressonância em diversos sentidos e contextos na Holanda, como na religião cristã e na infância, por exemplo. A inocência branca fornece uma posição segura para comportamentos contraditórios à autoimagem construída e reivindicada. Essa inocência é utilizada ao justificar comentários racistas - reportados como brincadeiras e sem intenção - e tradições nacionais. Isto é, argumentos que alegam brincadeira ou não intencionalidade ao tentar se defender de acusaçóes de racismo ("era apenas uma piada", "é uma tradição infantil", "eu não queria ofender") mobilizam o recurso da inocência. E esse recurso atua em um duplo sentido: abrange o não saber, mas, também, o não querer saber, conforme a epistemologia da ignorância proposta por Charles W. Mills (2007). Assim, com base em variados exemplos de racismo e sua reivindicação de inocência no cotidiano holandês (como comentários racistas em programas de TV, vivências pessoais, testemunhos), a autora, retomando Franz Fanon (2008), analisa a cisão na compreensão de si e de mundo de europeus brancos que lhes permite continuar a ter uma visão idealizada de si mesmos.

Contudo, tal inocência é acompanhada de violência, física e simbólica, especialmente quando ela é confrontada, algo que Wekker discute partindo dos conceitos de "melancolia pós-colonial", de Paul Gilroy (2005), e de "ignorância agressiva”, de Mills (2007). A inocência branca, portanto, estaria conectada aos privilégios e à violência do passado colonial, de modo que envolveria um contínuo trabalho para encobrir e ocultar o racismo estrutural e, assim, manter a suposta inocência.

A segunda categoria analítica na qual se sustenta o argumento da autora é a de arquivo cultural, de Edward Said (2011). O conceito refere-se às estruturas de conhecimento, afeto e ação presentes nas dinâmicas de configuraçôes de sentido e de representação nacionais. Trata-se de um repositório de memórias e de sentimentos que atua não apenas no sujeito, mas em políticas públicas, preceitos jurídicos, imaginário cultural e senso comum; isto é, são alicerces instituídos em séculos de domínio imperial. Nesse sentido, a ideia de Wekker é argumentar sobre como esse passado ainda está presente, uma vez que estruturas e dinâmicas coloniais continuam atuantes em diversas áreas (institucionais, culturais, intelectuais etc.), com a intenção de "trazer para o primeiro plano as memórias, o conhecimento e o afeto em relação à raça que foram depositados nas populaçôes metropolitanas e as relaçóes de poder inseridas dentro delas" (p. 19). Para analisar esse arquivo cultural, a antropóloga sugere uma leitura interseccional das maneiras pelas quais a economia racial imperial, em seus cruzamentos com gênero, sexualidade e classe, continua a operar nas formas dominantes de sentimento e de conhecimento, e como essas intersecçôes geram respostas agressivas, ao mesmo tempo que sáo refutadas pela sociedade.

Por fim, o terceiro conceito importante utilizado no livro, a autorrepresentaçáo branca holandesa dominante, diz respeito ao que Wekker chama de self metropolitano. Ela entende que a raça sempre foi a gramática organizacional e definidora da ordem social e da política imperial. Várias narrativas são mobilizadas na construção da identidade nacional, isto é, na definição do que é ser holandês: a constante luta e o trabalho coletivo contra a água, 
os mecanismos de resolução de disputas baseados na negociação, a resistência contra os espanhóis no século XVI, a idade de ouro (século XVII), a convivência pacífica entre diferentes crenças etc. Nenhuma dessas narrativas, contudo, menciona a questão racial ou o passado colonial do país; afinal, a descolonização seletiva manteve a lógica maniqueísta que torna impossível ser, simultaneamente, europeu e negro/muçulmano/imigrante/refugiado. O livro revela, com isso, que raça segue sendo o marcador que ordena situaçóes e práticas diárias, enquanto o discurso dominante segue negando que ela seja uma categoria significativa na formação da sociedade holandesa.

Outra questão importante pautada pela análise de Wekker é a de que o passado colonial da metrópole e suas colônias são dispostos no mesmo plano analítico, contrariando dois consensos. $\mathrm{O}$ primeiro, mais geral, é a forma generalizada de entender que o que ocorreu nas colônias não faz parte da história europeia e, portanto, não é parte constitutiva do arquivo cultural europeu. $\mathrm{O}$ segundo, de caráter mais local (digamos) é a abordagem, no mesmo plano, da história da metrópole e de todas as suas colônias, tendo em vista que a parte oriental do império holandês (Indonésia) é lembrada e compreendida de modo distinto da parte ocidental (Suriname e Antilhas).

Nessa medida, o primeiro capítulo apresenta três estudos de caso sobre as diversas formas pelas quais a raça adquire significados generificados, sexualizados e classistas, sendo parte, portanto, de um arquivo cultural e de regimes de verdade que se manifestam cotidianamente. De forma geral, os casos buscam explorar como o corpo e a pessoa negra são associados à uma hipersexualização, ao trabalho doméstico/braçal e à criminalização ${ }^{3}$.

Se o primeiro capítulo busca traçar as bases cotidianas do racismo holandês sob uma perspectiva interseccional, o segundo trata dos padróes discursivos invisíveis e silenciados que operam no Estado e na academia em relação às mulheres, desvelando como nessas esferas a posição de mulher branca é o grau zero a partir do qual as outras mulheres se diferenciam. Analisando as políticas públicas, as secretarias de estado, os departamentos e as disciplinas universitárias, Wekker demonstra como se estabelece uma separação entre secretarias de mu- lheres (brancas, é claro, pois não especificado), de minorias étnicas (ou seja, todas as outras mulheres) e de cooperação internacional para o desenvolvimento (mulheres do Terceiro Mundo). São três locais onde a raça aparece como o marcador social usado para separar e ordenar políticas e pesquisas. Esses repertórios organizacionais e discursivos são uma herança colonial, uma violência epistêmica que segue confirmando quem pertence e quem não pertence à ordem nacional. Segundo a antropóloga, as narrativas oficiais "utilizam-se de categorias binárias assimétricas e hierárquicas que permitem que o gênero e o grupo racial dominantes se autorrepresentem como neutros, não-generificados e não racializados/etnicizados" (p. 64).

No terceiro capítulo, Wekker interroga a intersecção entre gênero e raça na sociedade metropolitana holandesa do início do século XX, partindo de um caso psicanalítico em que três mulheres se descrevem em termos raciais (síndrome hotentote) e o psicanalista as diagnostica em termos generificados (complexo de masculinidade). A autora explora, então, o significado da substituição de raça por gênero no diagnóstico das mulheres, assim como os locais de produção e circulação dos discursos raciais e de gênero na sociedade metropolitana e colonial holandesa. $\mathrm{O}$ argumento é o de que as noçóes de eu e outro estão intimamente atreladas à gramática racial colonial, dinâmica que mantém intacto o racismo no país.

$\mathrm{O}$ quarto e quinto capítulos enfrentam dois símbolos do imaginário e da cultura holandesa: os direitos e as políticas LGBT $^{4}$ e a tradição do Zwarte Piet. O quarto capítulo, mais especificamente, trata das relaçóes entre raça e sexualidade, sugerindo uma reflexão sobre a ascensão da extrema direita e sua popularidade entre gays brancos. A nostalgia é elemento importante desse fenômeno, enfatizada nos discursos do partido de extrema direita - Party for Freedom (PVV). Trata-se de uma nostalgia difusa e constante no senso comum holandês branco, que se ressente de um Estado de bem-estar social que já não lhe garante privilégios e seguridade: nostalgia religiosa ("quando não havia tantos muçulmanos"), social ("quando a nação era branca e a divisão do trabalho era clara") e homossexual ("quando não havia muçulmanos atrapalhando a parada gay"). Nesse sentido, as narrativas racistas, islamofóbicas 
e ufanistas têm ressonância na população gay, branca e liberal. Por fim, a autora critica a "economia do desejo" e sua conexão com o passado colonial, problematizando a exploração e a sexualização dos corpos outros - negros e árabes, sobretudo. O que se busca demonstrar é como tais dinâmicas continuam atuando em práticas sociais diárias: "esses padrōes foram silenciosamente transmitidos para nós no século XXI e continuam a estruturar as reaçóes sexuais brancas sempre que um outro racializado/ etnicizado, seja muçulmano ou negro, entra em jogo" (p. 137). A argumentação ecoa a reflexão de bell hooks (1992) sobre como, desde tempos coloniais, o corpo do outro tem sempre como razáo de ser o prazer e a satisfação do homem branco.

O quinto e último capítulo analisa a infame e "mais querida" tradição holandesa: o personagem do Zwarte Piet (Black Pete ou Pedro Preto). A personagem é um homem ou mulher brancos pintados de preto (black face), com uma peruca afro, lábios pintados de vermelho, brincos de argola dourados e uma fantasia moura (Moor) - que fala de forma errada e simples, mimetizando um sotaque, até alguns anos atrás, surinamês e, hoje, marroquino. Nas diversas versóes desse folclore nacional, tal figura é um servo do bispo branco São Nicolau (Sinterklaas), que veio da Espanha (ou Turquia) e chegou à Holanda em meados de novembro. A festividade culmina no feriado de 5 de dezembro, quando presentes são entregues às crianças e adultos e brincadeiras com críticas pessoais são encorajadas. Em meados de outubro, os dois personagens começam a tomar conta da decoração e dos produtos de lojas e mercados e a aparecer em jornais, propagandas e programas de TV. Para a antropóloga, o Black Pete encarna o que Stuart Hall (1997) chamou de "degradação ritualizada", isto é, uma representação considerada tão normal que não requer justificação.

Wekker, neste capítulo, não busca apenas investir na análise da violência simbólica, do racismo, das hierarquias sociais e das desigualdades de poder, ou seja, dos resquícios coloniais dessa tradição degradante. ${ }^{5}$ Mais do que isso, sua questão é refletir por que os protestos contra essa tradição insuflam veementes e, por vezes, violentas respostas por parte da população branca holandesa. Wekker faz um apa- nhado histórico dos protestos contra o Zwarte Piet, desde a década de 1960 até os dias de hoje, investigando dez temas recorrentes nas reaçóes contra os manifestantes. Ao se defrontarem com esses protestos, os cidadãos brancos holandeses expressam, em sua indignação, tanto a inocência branca, quanto a autorrepresentaçáo imaginada de país tolerante e liberal - contudo, incapaz de autocrítica de seu passado colonial. Afinal, como tal figura poderia ser racista se a Holanda é, e sempre foi, cega à cor e tolerante às diferenças?

Wekker interpreta essa tradição racista, bem como a resistência à mudança por parte da população branca holandesa, na chave proposta por Gilroy (2005), de uma "melancolia pós-colonial". Tal melancolia recusa o trabalho de elaboração da memória do colonialismo e ativa um mecanismo de defesa que ou nega e justifica a violência e o passado colonial ou se coloca como a vítima maior de seu próprio império. Sob o ângulo de sua posição de holandesa negra, a antropóloga argumenta que esse espetáculo racista mimetiza, no limite, o que significa ser membro de uma cidadania imperial metropolitana e branca sob a égide de uma desigualdade violenta em relação aos negros e às populaçôes coloniais.

$\mathrm{Na}$ conclusão, Wekker narra um episódio de 2013, durante um evento de celebração dos 150 de abolição da escravatura. No evento, Saidiya Hartman leu parte de seu livro Lose your mother (2007), uma contra narrativa de uma garota escravizada a bordo do navio Recovery, que foi abusada, física e sexualmente, pelo capitão. À intensidade do que foi narrado, seguiu-se um silêncio, interrompido, entâo, por um homem branco de meia idade que se levantou e interpelou: "mas, e o capitāo?" Ora, os sentidos da questão são diversos. Primeiro, é de se observar que o homem se identifica mais com o capitão, o homem branco da narrativa, do que com a vítima - um padrão de identificação que não pode mais passar despercebido. Outro ponto é a própria inocência branca que permite e dá legitimidade a esse homem branco de falar sem pudor ou autocrítica logo após uma leitura sensível e intensa sobre raça, violência e colonialismo. Essa inocência levanta o problema dos lugares e dos direitos de fala: a quem é permitido falar e em que ordem? 
A descrição do episódio sustenta uma posição epistemológica e ética de Gloria Wekker: se não multiplicarmos as perspectivas e os lugares de fala, isto é, se não contarmos as outras histórias (dos escravizados, colonizados, subalternizados) que contradigam as histórias oficiais, ficaremos presos na narrativa do capitáo. Hegemônica e abonada por camadas de inocência branca e ignorância agressiva, essa narrativa dificilmente irá se dissipar sem conflito. Porém, segundo alerta a autora, os tempos do "não saber, da ignorância racial e da inocência branca já se passaram faz tempo" (p. 167).

\section{Notas}

1 Em português, The Netherlands pode ser traduzido como Países Baixos ou Holanda. Opto pelo termo Holanda, pois a autora se refere, na obra, ao país localizado no continente europeu.

2 Todas as traduçóes do livro resenhado são de minha autoria.

3 Esses tropos são, também, encontrados em outros países europeus, nos Estados Unidos e no Brasil, por exemplo. Sobre isso, ver hooks (1992).

4 A Holanda foi o primeiro país do mundo a reconhecer o casamento homoafetivo, em 2001.

5 Para uma análise da tradição do Zwarte Piet, ver também Smith (2014) e Pijl e Goulordova (2014).
HARTMAN, Saidiya. (2008), Lose your mother: a journey along the atlantic slave route. New York, Farrar, Straus \& Giroux.

HOOKS, bell. (1992), Black Looks: race and representation. Boston, South End Press.

MILLS, Charles W. (2007), "White ignorance", in S. Sullivan e N. Tuana (eds.), Race and epistemologies of ignorance, Albany, State University of New York Press.

PIJL, Y. van der; GOULORDOVA, K. (2014), "Black Pete, 'Smug Ignorance' and the value of the black body in post-colonial Netherlands". New West Indian Guide, 88 (3-4).

SAID, Edward. (2011), Cultura e imperialismo. São Paulo, Companhia das Letras.

SMITH, J. L. (2014), “The Dutch Carnivalesque: blackface, play, and Zwarte Piet”, in P. Essed e I. Hoving, Dutch racism, Amsterdam, Rodopi.

\section{BIBLIOGRAFIA}

FANON, Franz. (2008), Pele negra, máscaras brancas. Salvador, Edufba.

GILROY, Paul. (2005), Postcolonial Melancholia. Nova York, Columbia University Press.

HALL, Stuart (ed.). (1997), Representation: cultural representations and signifying practices. Londres, Sage.

HARAWAY, Donna. (1995), “Saberes localizados: a questão da ciência para o feminismo e o privilégio da perspectiva parcial". Cadernos Pagu, 5: 7-41. 